\title{
Research and Practice of the Industry-Study-Research Cooperative \\ Education of the Tourism Management
}

\author{
Jiantao Wang ${ }^{1}$ \\ ${ }^{1}$ Xi' an International University, Xi' an, Shannxi, 710077
}

\begin{abstract}
KEYWORDS: Research, Practice, Cooperative Education, Tourism Management, Industry-Study-Research
\end{abstract}

\begin{abstract}
Combination of the Ministry of Education is an important indicator of university talent training level assessment standards. In order to optimize the management of professional personnel training mode Cooperative Practice of tourism education, tourism management to enhance the level of professional personnel, through the Tourism Management Training Mode, Cooperative Education model, features and operation mechanisms and practice of elaboration, analysis, presented the results of research and the idea and practice of tourism management professional cooperative education.
\end{abstract}

\section{Introduction}

With the development of higher education, research cooperative education's important role in higher education is increasingly perceived as the education sector, the Ministry of Education in undergraduate higher education teaching personnel training level assessment criteria, the "research" combined as an important evaluation index. Philosophy and practice of Cooperative Education is both a set of quality university education, entrepreneurship education and professional education in one mode of education, but also cultivate high-quality talent, accelerate scientific and technological achievements in industry, services, the main battlefield of economic construction, an important measure. Cooperative education is both suitable for cultivating academic talent, but also for Applied Talents mode. "Industry-University" means that a combination of teaching and production practice. "Production and research" refers to the combination of scientific research and production practice. "Research study" means that a combination of research and teaching areas.

Occupation characteristics of tourism higher education, professional education must decide such as business services, starting from the actual needs of enterprises, to meet the various requirements of business professionals to solve various problems in the business, providing intellectual support. In recent years, the rapid development of cooperation in all levels of government and business and tourism institutions of higher learning, a large number of transverse research universities to tourism, the tourism industry needs explanation academic research is growing. Feedback from the job market and tourism industry employment point of view, requires colleges and universities teaching achievement and tourism industry there is a certain gap. On the one hand a large number of students are unable to favorite "advanced" positions, on the other hand the lack of people shouting in the industry, the lack of "high quality and can do specific things" talent. This contradiction highlights the urgency of further integration of production and research. 
Cooperative education is a kind of students overall quality, comprehensive ability and employability and competitiveness, focusing on the use of schools and businesses in two different environments and educational resources education, students take classroom teaching and practical work, teachers' participation in business issues organic combination of culture for the employer requires a comprehensive model of education quality and innovative ability of talent, that is, its basic features is a training model. Running way tourism cooperative education universities in line with the characteristics of tourism management teaching, but also reflect the characteristics of the times higher education in the new century, the result is the ultimate realization of the "learning to do production, to produce secondary school to research with production, research and promote each other, "the virtuous cycle, really" need double, win-win, interactive "common development.

\section{The Problems in Cooperative Education and Practice of University Management Tourism}

The first is the practice of teaching and research cooperation in the "production" of. On the one hand is the relationship between business and tourism management contract between teaching, not many enterprises and tourism management professional relationship; the other hand, even if related businesses to provide opportunities for social practice, but mostly because of labor shortage, can students without Talented as tourism enterprises to develop. Partly because tourism management complexity of their work; the other is the school's school system, curriculum and evaluation methods is not flexible enough, so that teaching school personnel will be restricted. At present high-quality personnel of tourism management than before has been significant growth in tourism management research but people are a minority, the majority tend to be economic choice.

Currently, some research teaching model of lack of its own characteristics, multi-copy other schools at home and abroad. "Production" is not the presence of the heavy weight of the drawbacks; "learning" the existence of the problem of inadequate professional skills of teachers; "research" Problems of scientific research under the low conversion rate.

Which involves teachers, students, cooperative enterprises, research institutes evaluation and encouragement. The university lacks cooperative practice teaching practical incentives, so that university teachers more busy job classification at the expense of teaching and research cooperation innovation research practice teaching mode. Again, the national lacks of clear legal provisions on the responsibility and obligation to practice teaching and research cooperation undertaken by the tripartite Universities. Finally, the staff engaged in tourism management specialty research practice teaching high mobility, the lack of appropriate policies and regulations constraints and incentives, unable to retain talent.

\section{The Necessity of Tourism Management Cooperation Practice Teaching Model}

First, as social and economic development, the rapid development of tourism, tourism is the lack of employees, especially senior tourism management. According to the authorities is expected by 2020, China's tourism growth in the number of employees will exceed one million, and the current Chinese universities only provide about 150,000 graduates every year.

Secondly, the Cooperative practice teaching mode to meet the requirements of professionals Higher Education Institutions. From the training objectives, the practice of teaching and research cooperation in line with employment-oriented high-level personnel training needs. From the point of view of teaching mode, practice teaching and research cooperation both professional, practical, practical needs. 
Again, the practice of Cooperative Teaching Model is in line with the "double program" theory and practice syllabus. Training targeting Cooperative practice teaching, teacher certification, teaching content design, teaching curriculum, practical teaching methods more suited Universities tourism management market, practical needs under the new situation.

\section{Suggestions for Tourism Management Cooperative Education}

Government should play a leading role in improving Cooperative Mechanism government run power dominant in Cooperative innovation, it is not only to promote research cooperation innovation leader, organizing coordinator, supervisor norms, but also its direct service and important investors. In order to improve the competitiveness of enterprises and the overall national strength, the government should take a variety of forms to increase direct investment in support of Cooperative Development. Cooperative development of the organization and coordination of service policies, accelerate technological innovation system with enterprises as the main body, a combination of research, efforts to promote and strengthen the dominant position in the production and research cooperation, building research cooperation by the relevant legislation innovation system, improve the operation of power and research cooperation mechanism to promote cooperation between enterprises and universities.

Have a business of teaching and experimental base is strong support for the implementation of tourism institutions of higher learning and research cooperative education have a business teaching experimental base, on the one hand to meet the needs of tourism management professional teaching situation, on the other hand as a professional tourism management Cooperative Education base. Foreign Cooperative Education more successful tourism institutions, has its own business teaching experimental base, such as the Hotel Management School in Lausanne, Switzerland, the Cornell School of Hotel Administration of the United States and so on. We have a business teaching experimental base, tourism institutions of higher learning can be flexible placement in time, either arrange student internships in service positions, and can arrange internships in management positions, improve the practice effect, the real train the students sense of service and management capacity, but also to effectively enhance the professional skills of teachers, promote transformation of scientific research. Can this base, the educational resources of tourism universities into the background of economic development in tourism, real Cooperative Education. Tourism Management Combination The more closely the development of the more healthy, trained in tourism management majors more competitive.

Colleges and universities should strengthen the research team and the platform on the basis of the establishment of the Tourism Development and Planning Institute, Development Research Center and other research management platform to further strengthen tourism management discipline research team-building efforts to enhance tourism enterprises, social service capacity is good the basic premise of Putian College of Tourism management cooperative Education. Through the establishment of the research team, the old and young, school-enterprise cooperation, and promote the "double" teacher training, but also to change the number of professional teachers to meet only by teachers and students, friends, relations, to find a few subjects, take a little funds, so cooperative Education organized in a high level state. Research team building and platform construction rely on each other, promote each other, forming a virtuous circle, in order to carry out cooperative education has laid a solid foundation.

Guide research teams offer of services for the industry and local cooperation in research, universities should focus on tourism through policy, institutional guide, motivate research team in-depth tourism enterprises, promote the development of cooperative education. Research on 
school policy, stressed the research work to establish ideology initiative for the industry and local economic and social development services.

Clear guidelines, and improve cooperation in education and research personnel training system based on the low degree of tourism enterprises team of practitioners, employees do not have a lot of tourism management professional background, senior technicians account for travel services are significantly lower proportion of employees, particularly good service, and business management, to understand the management of application-oriented, hands-on in this situation is the lack of grass-roots workers, combined with the tourism management professional orientation, presented professional development to serve local economic and tourism development in Fujian need to mainly focus on tourism management professional management personnel training, focusing on the combination of education and professional development of local tourism, professional training objectives emphasize qualifications standards, industry standards and corporate standards. Professional characteristics reflected the emphasis towards practical and direction of international development, extending support to basic disciplines, focusing on basic skills training and professional capacities to achieve in tourism management and services have both theoretical knowledge and practical ability talents.

Pay attention to the quality of education practice, promoting the "industry-academia" practice that combines education is an important part of higher education in tourism, tourism internship Education success or not directly affect the normal development of cooperative education, affecting the sustainable development of tourism higher education. Tourism enterprises should ensure the continuity of the internship, students should practice with occasional meetings and conversations, strengthening trainee in a statement, report writing work, ability and other aspects of the negotiations and management guidance and training, limited to a changing student internships sector downscale repetitive line service operations; tourism institutions of higher learning should be combined with the actual situation of tourism enterprises, tourism enterprises arrange staff to complete tasks outside practice guidance to ensure that guide students before practice, practice and practice in monitoring post summarizing the successful completion; students need to strengthen the internships, internships significance of understanding and awareness, in order to clarify the objectives and norms of practice internship education, to promote "combining production."

\section{Conclusion}

Cooperative teaching practice is an open education model, breaking the shackles of books on the culture of tourism management students' sense of service, professionalism has a vital role. At the same time, help test theories of knowledge level of the students, to enhance the professional and technical capacity, to cultivate a more market demand for tourism management.

\section{Reference:}

[1] Bao Wenbo, all raw guitar, Ning Po-wide Cooperative Practice Teaching Model [J] Architectural Education, 2012,21 (4): 111-113.

[2] Guo Xu Dong tourism management undergraduate teaching and research integration model [J] Pearl Education Forum, 2011,3 (1): 162-163.

[3] Wang Jian depth research of Tourism Trinity Operating Mechanism [J] Tourism Sciences, 2012,26 (1): 1-6.

[4] Chen Ping Tourism Management Practical Teaching Quality Evaluation System [J] everyone, 2011, (2): 226-227. 
[5] Xiong Jihong Research Universities and Tourism Management Teaching Evaluation System [J] Higher Correspondence Education, 2009,22 (1): 25-31. 